\title{
Anxiety as an Aggravating Factor During Onset of Focal Dystonia in Musicians
}

\author{
Hans-Christian Jabusch, M.D., and Eckart Altenmüller, M.D.
}

\begin{abstract}
Focal dystonia in musicians is a task-specific movement disorder that in many cases leads to the end of musical careers. In a recent study, perfectionism and anxious traits were found to be elevated in musicians with dystonia. Dynamics of different anxiety disorders and their possible role during the development of musician's dystonia still are unclear. Dystonic musicians $(n=20)$ were investigated by means of self-estimation and compared with healthy musicians $(n=30)$ and musicians with chronic pain syndromes $(n=$ 20). Participants completed a questionnaire focusing on different anxiety disorders, particularly with regard to their dynamics. Musicians with focal dystonia more often reported social phobia and specific phobias than healthy musicians. In the retrospective analysis, these differences already were present before onset of dystonia. Musicians who later developed focal dystonia more often suffered from specific phobias than musicians who later developed chronic pain. Musicians with chronic pain more often reported free-floating anxiety compared with healthy musicians. In the subscale stage fright, no significant differences were observed between the groups. The pattern of specific phobias and social phobia were reported to have been preexisting before the onset of dystonia. Anxiety and perfectionism may be aggravating factors during the development of musician's dystonia. Med Probl Perform Art 2004; 19:75-81.
\end{abstract}

Cocal dystonia (FD) in musicians, also called musician's F cramp, is a task-specific movement disorder that manifests as a painless muscular incoordination or loss of voluntary motor control of extensively trained movements while a musician is playing the instrument. ${ }^{1-5}$ For musicians who are affected, FD is highly disabling and in many cases ends musical careers. The pathophysiology is unclear. For many decades, psychological factors were believed to be essential for the development of task-specific FDs and were overemphasized in the assumed pathomechanism. In 1888, Gowers ${ }^{6}$ subsumed writer's cramp and related cramps under the term occupational neuroses. At that time, neurosis was used as a term for a disease when a physical origin was assumed but a clear cause could not be described. Later, the meaning of the term shifted in the direction of a neurotic illness. As a consequence, for almost a century, occupational cramps were regarded as psychological diseases by most authors. ${ }^{7}$ In 1982 , Sheehy and Marsden ${ }^{8}$ reported the absence of psychiatric disorders in patients with typist's and writer's cramp. They

Dr. Jabusch and Dr. Altenmüller are at the University of Music and Drama, Institute of Music Physiology and Musicians' Medicine, Hannover, Germany.

Address correspondence and reprint requests to: Eckart Altenmüller, MD, Institute of Music Physiology and Musicians' Medicine, University of Music and Drama, Hohenzollernstrasse 47, 30161 Hannover, Germany. email:altenmueller@hmt-hannover.de. stated that occupational cramps are symptoms of a physical illness, and they used the term focal dystonia. ${ }^{8,9}$ Subsequently the neuropathophysiology of FD was investigated in numerous studies. ${ }^{10-12}$ The findings included alterations in the basal ganglia circuitry 13,14 and dysfunctional plasticity in the sensory thalamus ${ }^{15,16}$ and somatosensory $\operatorname{cortex}^{17-19}$ and changes in the activation patterns of the sensorimotor corte $^{20-22}$ and alterations in sensorimotor integration..$^{23,24}$

At the same time, many studies focused on psychiatric comorbidity in patients with various forms of dystonia. ${ }^{25-30}$ Depressive, anancastic, sensitive, and hysteric traits were observed in patients with writer's cramp. ${ }^{27}$ Anxiety occasionally was seen in patients with writer's cramp. ${ }^{31-33}$ It was discussed controversially whether psychological findings were present before onset of dystonia ${ }^{26,34}$ or whether patients showed secondary psychoreactive processes. ${ }^{35}$ In contrast, in a study with 22 patients with writer's cramp no significant differences were found compared with a matched normal control group using the Crown-Crisp Experiential Index. ${ }^{30}$ This questionnaire assessed traits and symptoms relevant to neurotic illness and contained three anxiety subscales (freefloating anxiety, phobic anxiety, somatic anxiety). Scheidt et $\mathrm{al}^{29}$ investigated patients with blepharospasm and patients with hemifacial spasm using the SCL-90R and found scores of psychopathology ranging close to normal in both patient groups. Phobic anxiety was more pronounced, however, in patients with blepharospasm than in controls and in patients with hemifacial spasm. Social phobia was found in patients with spasmodic torticollis. ${ }^{36}$

Until more recently, psychological conditions of musicians with FD had never been investigated. In one study, psychological conditions of dystonic musicians were compared with those of healthy musicians and of musicians with chronic pain (CP) syndromes. ${ }^{37}$ Perfectionism and anxious traits were reported more often in musicians with FD compared with healthy musicians. In both patient groups, anxiety was found more often than in healthy musicians. Anxious traits and perfectionism were reported to have been present before onset of FD, and they could not be interpreted as secondary psychoreactive phenomena.

In this article, we report the dynamics of different anxiety disorders in musicians with FD. Findings were compared with those in healthy musicians and musicians with CP syndromes. Based on clinical observations, the underlying hypothesis was that dystonic musicians more often have social phobias and specific phobias than healthy musicians and that these anxiety disorders were present before onset of 
TABLE 1. Distribution of Instruments in Patient Groups and Normal Controls

\begin{tabular}{lccc}
\hline Group & FD & CP & Control \\
\hline Keyboard instruments (no.) & 4 & 10 & 8 \\
String instruments (no.) & 2 & 7 & 9 \\
Woodwinds (no.) & 5 & 1 & 4 \\
Brass (no.) & 4 & 0 & 8 \\
Plucking instruments (no.) & 5 & 2 & 1 \\
\hline
\end{tabular}

$\mathrm{CP}$, chronic pain; FD, focal dystonia.

dystonia. The possible role of anxiety during development of FD is discussed.

\section{PATIENTS AND METHODS}

\section{Patients and Controls}

All participants included in the study were able to speak, read, and write German fluently. Patients were recruited randomly from the outpatient clinic of the Institute of Music Physiology and Musicians' Medicine of the University of Music and Drama in Hannover, Germany. They underwent complete neurologic and psychiatric examination and were diagnosed by at least one of the authors (E.A.). Two groups of patients were included. One sample comprised 20 professional musicians ( 16 men and 4 women; age $36.7 \pm 6.4$ years) who had been diagnosed with task-related FDs. Three out of 20 patients were brass players with perioral dystonias; the other 17 patients had hand dystonias, which manifested in the typical manner as painless cramping of one or more fingers while the patients were playing their instruments. The individual duration of the disorder was 3 to 12 years $(6.9 \pm$ 2.6 years [mean $\pm \mathrm{SD}]$ ) at the time of the study. Twelve patients noticed additional dystonic movement patterns in other activities, such as writing (five patients), on the computer keyboard (four patients), or in everyday activities; the onset of these additional symptoms occurred after the onset of musician's cramps. Patients with other neurologic disorders or secondary dystonias were excluded from the study.

The second sample of patients comprised 20 professional musicians ( 5 men and 15 women; age $32.6 \pm 8.7$ years) with CP syndromes related to playing their instruments. Pain was localized in the hand or arm region or both. The individual duration of CP ranged from 6 months to 30 years $(4.9 \pm 6.9$ years) at the time of the study.

A third group consisting of 30 professional musicians was recruited as healthy controls (16 men and 14 women; age $32.9 \pm 5.4$ years). They were working in German orchestras, in music schools, and as freelance professional musicians. By means of questionnaires, they were asked if they had any kind of ill health, especially movement disorders or CP. Musicians with any somatic complaints or neurologic or psychiatric diseases were excluded from the normal control sample. The distribution of instruments in all groups is given in Table 1.

\section{Methods}

The assessment of anxiety disorders was based on self-estimation using a questionnaire comprising six questions focusing on anxiety disorders. These were subgrouped as considerable stage fright; panic attacks; free-floating anxiety; agoraphobia; social phobia; and specific phobias, such as acrophobia and claustrophobia. The respective symptoms were explained to the subjects, and they were asked whether they felt that these anxieties were present or absent. To investigate whether certain anxieties were preexistent before the onset of FD or CP in the patient groups, a second step was added: Subjects were asked to decide whether these particular anxieties had been present or absent before onset of their disorders and since when the respective anxieties were experienced. Informed consent was obtained from all subjects. They were instructed to fill out the questionnaires without the presence of other persons. Distribution and collection of the questionnaires was done by mailing; precise written explanations were attached.

Statistical analyses of the differences of anxiety disorders between the groups was performed using $\chi^{2}$ tests. Two-tailed Fisher's exact tests were applied when $\chi^{2}$ tests were not possible due to methodologic requirements. $\chi^{2}$ tests and Fisher's exact tests were performed separately for evaluation of the differences in the anxiety subscales before and after onset of the disorders. Differences between groups with a $p$ value $<0.05$ were considered statistically significant.

\section{RESULTS}

All questionnaires were filled out properly and could be included in the analysis. Patients were asked to specify whether their tendencies concerning anxieties had been the same or different before and after the onset of their diseases. In this respect, conclusive statements could be obtained in all patients with FD and in 19 of 20 patients with CP.

Analysis of the different anxiety subscales yielded the following results (Figure 1): Musicians with FD experienced social phobias remarkably more often than healthy musicians (twotailed Fisher's exact test [Fisher's], $p<0.01$ ), which already had been the case before onset of FD (Fisher's, $p<0.01$ ). Patients with CP did not report more social phobias having been preexisting before onset of CP compared with healthy musicians. This comparison revealed a significant difference (Fisher's, $p<$ 0.05), however, after development of CP due to an increase of social phobias in these patients after onset. Only patients with FD significantly more often reported specific phobias, such as acrophobia or claustrophobia, compared with healthy musicians $\left(\chi^{2}=4.69, p<0.05\right)$. These specific phobias had already been present before they developed FD. Musicians who later developed FD more often suffered from specific phobias than musicians who later developed CP (Fisher's, $p<0.05$ ). The opposite result was found in the subscale free-floating anxiety: Only patients with CP significantly more often reported freefloating anxiety than normal controls. This was the case before $\left(\chi^{2}=5.21, p<0.05\right)$ and $\left(\chi^{2}=8.0, p<0.01\right)$ after onset of CP. In the subscales considerable stage fright, panic attacks and 


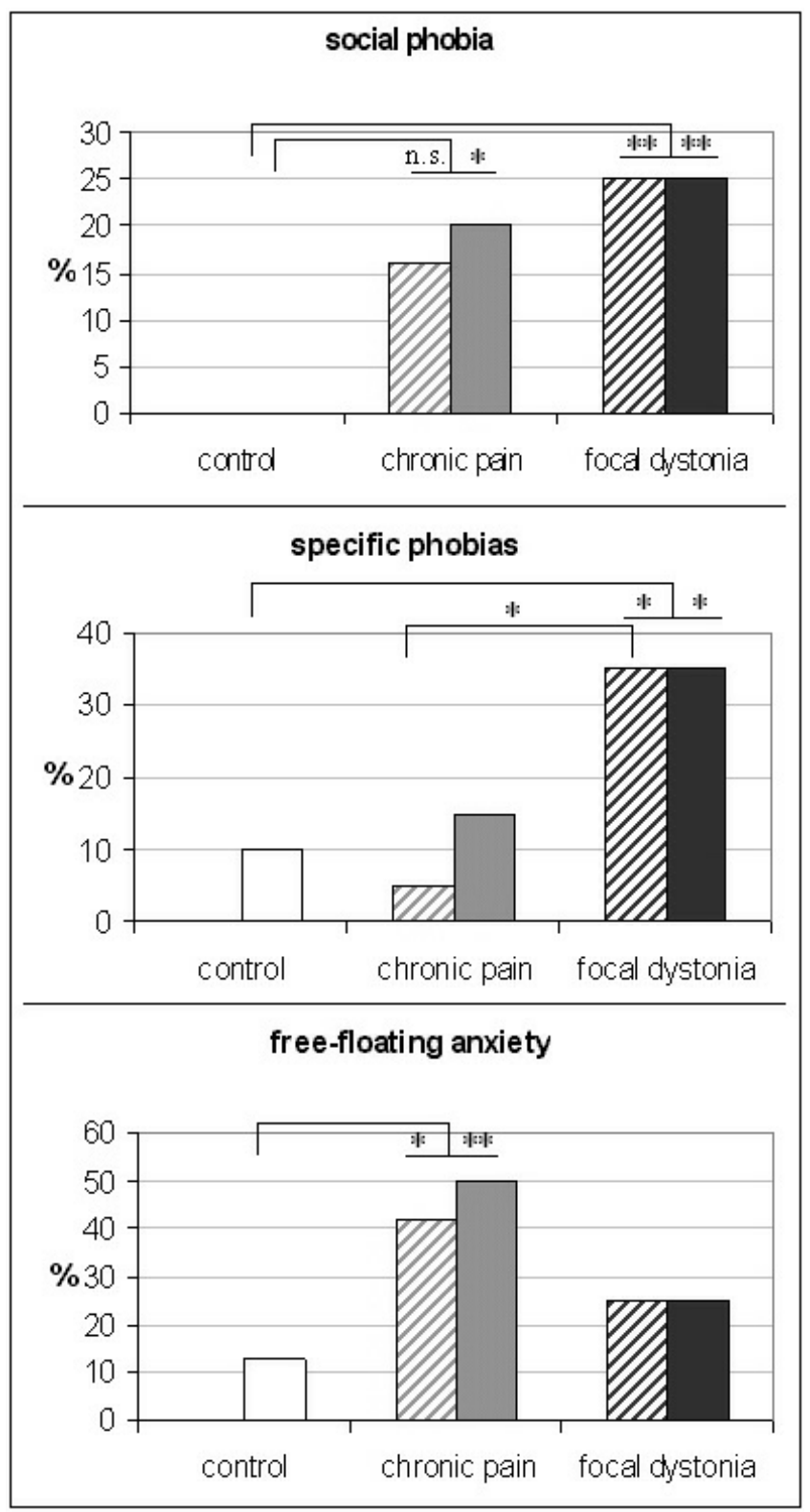

FIGURE 1. Anxiety disorders in controls and musicians with chronic pain and with focal dystonia. Percentage of subjects (of respective groups) who reported social phobia, specific phobias, and free-floating anxiety. Hatched bars: percentage with anxiety before onset of the respective playing-related problem. Filled bars: percentage with anxiety after onset of the respective playing-related problem. ${ }^{*} p<0.05 .{ }^{* *} p<0.01$. n.s., not significant.

agoraphobia, no significant differences were observed between any patient group and healthy musicians (Figure 2). No significant differences were found in any of the anxiety subscales between male and female subjects.

\section{DISCUSSION}

\section{Inventories}

The present study aimed at the assessment of different anxiety disorders in musicians before and after the onset of

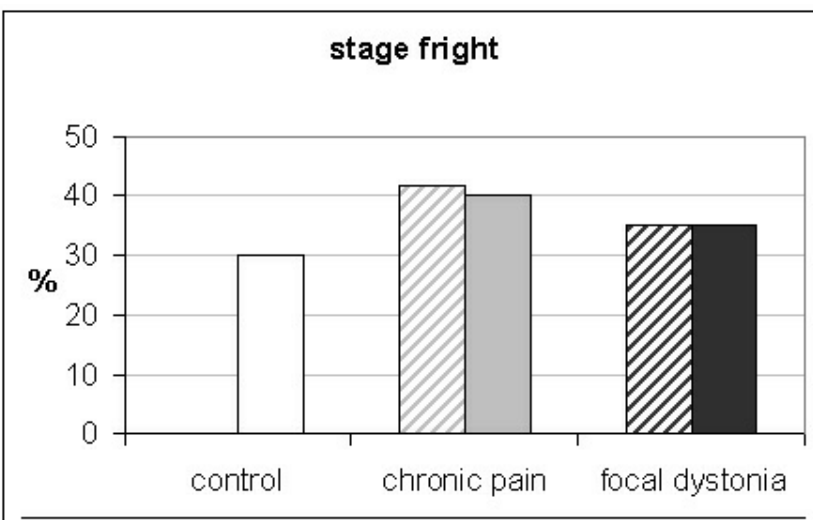

panic attacks

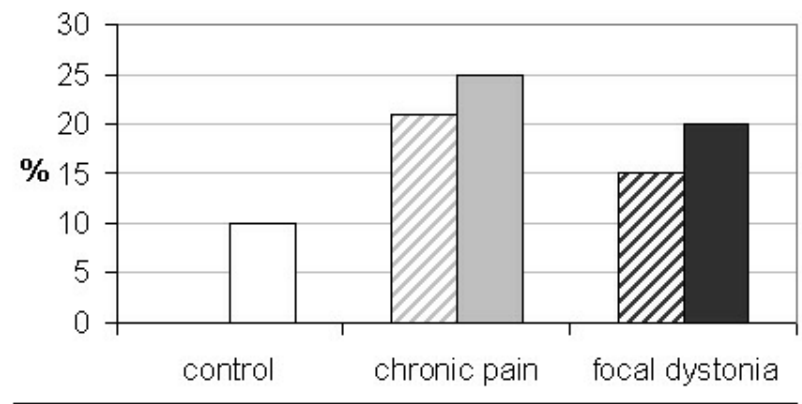

agoraphobia

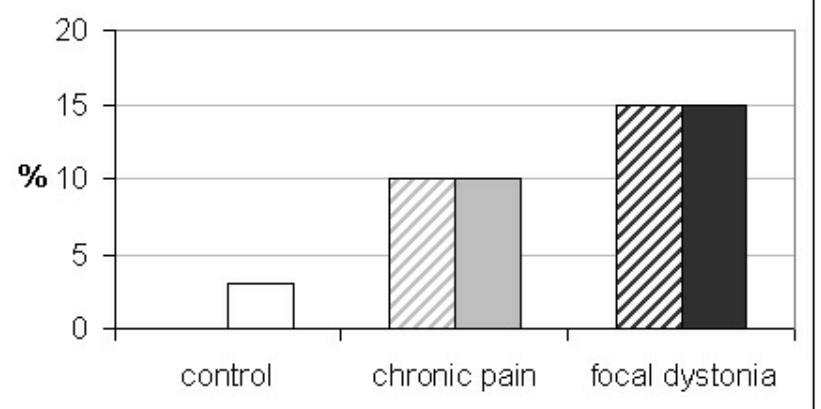

FIGURE 2. Anxiety disorders in controls and musicians with chronic pain and with focal dystonia. Percentage of subjects (of respective groups) who reported considerable stage fright, panic attacks, and agoraphobia. Hatched bars: percentage with anxiety before onset of the respective playing-related problem. Filled bars: percentage with anxiety after onset of the respective playing-related problem.

FD and the comparison with healthy musicians and musicians with $\mathrm{CP}$ syndromes. Because of a prevalence of FD between 1:200 and 1:500 in professional musicians ${ }^{5}$ with the consequence of a low incidence, a prospective study with the particular aim of assessing anxiety disorders in musicians before the development of FD was not realizable. For retrospective comparison of anxiety disorders before and after the onset of FD or CP syndromes, state-trait anxiety inventories were not applicable. Because the duration of FD was $6.9 \pm$ 2.6 years and duration of $\mathrm{CP}$ was $4.9 \pm 6.9$ years at the time of the study, it could not be excluded that anxiety traits 
detectable by state-trait anxiety inventories might have developed after onset of the respective playing-related problem. The temporal relationship between the onset of anxiety traits and the onset of playing-related problems could not be detected using state-trait anxiety inventories. A retrospective inquiry was undertaken that was based on personal recollection of the patients. Under the given circumstances, this procedure was the only practical approach to obtain the desired information. Although the exact date of onset of anxieties in the past might not be determinable, a retrospective inquiry does provide an image of individual developments of these psychological conditions in the past.

\section{Findings}

Social phobias and specific phobias occurred more often in dystonic musicians than in healthy musicians. This already was the case before onset of FD. The comparison between both patient groups revealed a clear difference: Musicians with FD more often suffered from specific phobias before onset of FD compared with CP patients before onset of CP. In the dystonic group, all patients described these anxieties as long-term phenomena already present before FD. As a limitation of the study, these retrospective reports are subject to bias and not always reliable. In view of the unambiguity and consistency of the reports of all patients with FD, however, we postulate that anxiety may have been preexisting and was not a psychoreactive phenomenon. Musicians with FD were reported to display more perfectionism than healthy musicians. ${ }^{37}$ In the retrospective analysis, this difference already was present before onset of FD. In patients with $\mathrm{CP}$, no higher level of perfectionism was found compared with healthy musicians. Taken together, dystonic musicians showed a pattern of social phobia and specific phobias and of exaggerated perfectionism before onset of dystonia, which was not seen in healthy musicians or musicians with CP. In view of the findings for musicians with FD, the question arises whether the described psychological patterns with anxiety and exaggerated perfectionism might have an impact on the development of FD in musicians.

\section{Anxiety as an Aggravating Factor During Onset of Musician's Dystonia}

There is evidence that FD is a complex disorder accompanied by neuropathologic findings, such as alterations in the basal ganglia circuitry ${ }^{13,14}$ and dysfunctional plasticity in the sensory thalamus ${ }^{15,16}$ and somatosensory cortex. ${ }^{17-19}$ Preexisting anxiety and perfectionism may serve as additional, aggravating factors in the development of musician's FD in the following way. During onset of musician's FD, dystonic movements are realized as disturbing and threatening, especially by musicians with an inclination toward anxiety and extreme perfectionism. Dystonic movements might become a focus in terms of a specific phobia in musicians with these tendencies. This focus might induce the cascade of emotionally induced memory consolidation that previously has been described and applied to different forms of memory and that mainly relies on noradrenergic activation of the basolateral amygdala. ${ }^{38-40}$ The primary motor cortex as an essential locus of representation of digital motor sequences ${ }^{41}$ receives a basolateral amygdala projection. ${ }^{42}$ We suggest that during the development of musician's FD in predisposed individuals, basolateral amygdala-mediated consolidation of dystonic movements as dysfunctional motor programs in the primary motor cortex may be an aggravating epiphenomenon (Figure 3).

\section{Findings in Musicians with Chronic Pain}

The findings in musicians with CP harmonize with other reports on $\mathrm{CP}$ patients. The association between anxiety and CP often has been described for CP syndromes in different sites. ${ }^{43-45}$ In particular, social phobia was found to be related to physically unexplained CP in a study with 130 patients. Additionally, in keeping with the findings of the present study, agoraphobia was found minimally pronounced in CP patients. ${ }^{46}$ Free-floating anxiety, which was present more often in CP musicians than in healthy musicians of this study, turned out to be a predictor for early retirement in patients with CP. 47

There was a preponderance of male musicians in the sample of patients with FD. This finding is in agreement with consistent reports about higher prevalence of musician's dystonia in men. ${ }^{2-5,48,49}$ A preponderance of female musicians in our sample of CP patients is in keeping with other reports of a higher prevalence of CP syndromes in women. ${ }^{50}$ Gender distribution was almost balanced in the sample of normal controls. Beside of the group affiliation, gender also was a factor in the analysis: no differences were found between male and female musicians in any of the anxiety subscales. This result suggests that the differences between the groups as described for the subscales specific phobia, social phobia, and free-floating anxiety were not distorted by different gender distributions in the groups.

No significant difference was found in the subscale of considerable stage fright between all groups. The percentage rate for stage fright (30\% in healthy musicians) in this study was higher than in other reports (in Fishbein et al's ${ }^{51}$ study, 24\% of 2,212 orchestra musicians had stage fright). This might be explained with the fact that our samples comprised orchestra musicians and freelance professional musicians who also were playing as soloists. Our findings suggest that stage fright does not increase the susceptibility for FD in musicians.

\section{CONCLUSION}

The occurrence of anxieties, such as specific phobias and social phobias, was higher in musicians with FD than in healthy musicians. These anxieties were present before onset of FD. In a subgroup of dystonic musicians with an inclination toward perfectionism and anxiety, in particular specific anxieties, this psychological constellation might be an aggravating factor in the development of FD. In such patients, early intervention during onset of FD including management of these particular psychological patterns, might be benefi- 


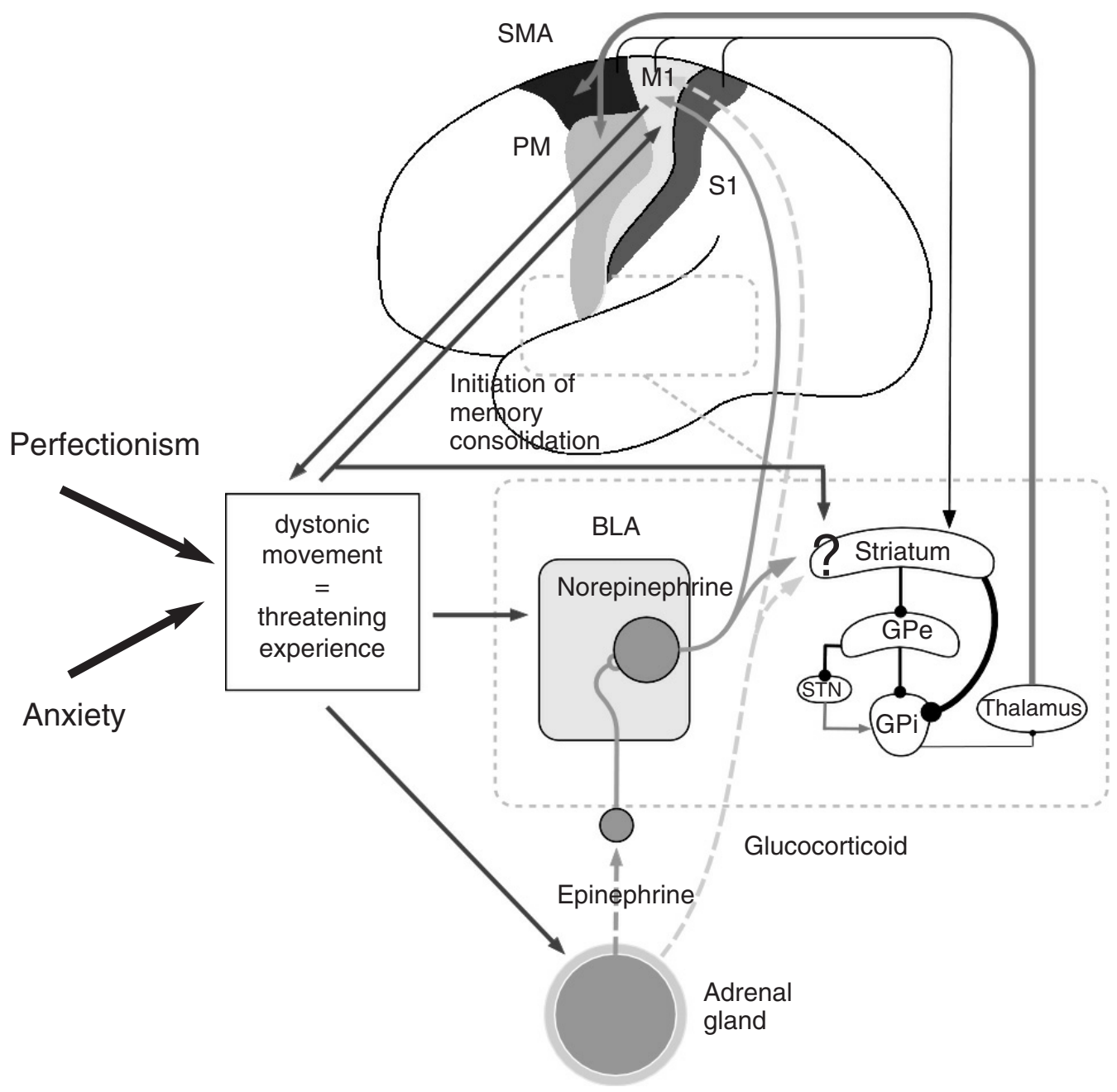

FIGURE 3. Anxiety and perfectionism as aggravating factors in the development of musician's dystonia. Perfectionistic and anxious musicians experience dystonic movements as emotional stress, which may cause the release of epinephrine and glucocorticoids from the adrenal glands. Epinephrine via stimulation of the nucleus of the solitary tract causes an increased norepinephrine release of the basolateral amygdala (BLA). ${ }^{52,53}$ This $\beta$-adrenergic activation within the amygdala is a prerequisite for memory-enhancing effects of glucocorticoids. ${ }^{54}$ The primary motor cortex (M1) is an essential locus of representation of digital motor sequences ${ }^{41}$ and receives a BLA projection. ${ }^{42}$ Emotion-dependent consolidation of dystonic movements in M1 might be an aggravating factor during the development of musician's dystonia. It is unclear whether the modulary effects of the BLA influence the basal ganglia circuitry. GPe, lateral globus pallidus; PM, premotor cortex; S1, somatosensory cortex; SMA, supplementary motor area; Gpi, medial globus pallidus; STN, subthalamic nucleus. (Parts adapted from McGaugh JL: Memorya century of consolidation. Science 2000;287:248-251.)

cial. Further studies are required to illuminate the possible involvement of the limbic system in the pathogenesis of musician's dystonia.

\section{ACKNOWLEDGMENT}

We express our appreciation to Sandra Verena Müller, Ph.D., from the Institute of Neuropsychology (Otto von Guericke University, Magdeburg, Germany) for valuable discussion of the topic.

\section{REFERENCES}

1. Jankovic J, Shale H: Dystonia in musicians. Semin Neurol 1989;9: 131-135.

2. Lederman RJ: Focal dystonia in instrumentalists: clinical features. Med Probl Perform Art 1991;6:132-136.

3. Brandfonbrener AG: Musicians with focal dystonia: a report of 58 cases seen during a ten-year period at a performing arts medicine clinic. Med Probl Perform Art 1995;10:121-127.

4. Frucht SJ, Fahn S, Greene PE: The natural history of embouchure dystonia. Mov Disord 2001;16:899-906.

5. Altenmüller E: Causes et traitements de la dystonie de fonction chez les musiciens. Medicine des Arts 2001;36:19-27.

6. Gowers WR: A Manual of Diseases of the Nervous System, Vol. 2. London, Churchill, 1888, pp. 656-674.

7. Brain WR: Diseases of the Nervous System. London, Oxford University Press, 1933; pp. 804-806.

8. Sheehy MP, Marsden CD: Writer's cramp-a focal dystonia. Brain 1982;105:461-480.

9. Marsden CD, Sheehy MP:Writer's cramp. Trends Neurosci 1990; 13:148-153.

10. Berardelli A, Rothwell JC, Hallett M, et al: The pathophysiology of primary dystonia. Brain 1998;121:1195-1212.

11. Hallett M: The neurophysiology of dystonia. Arch Neurol 1998;55: 601-603.

12. Lim VK, Altenmüller E, Bradshaw JL: Focal dystonia: current theories. Hum Mov Sci 2001;20:875-914. 
13. Naumann M, Pirker W, Reiners K, et al: Imaging the pre- and postsynaptic side of striatal dopaminergic synapses in idiopathic cervical dystonia: a SPECT study using ${ }^{[123 I]}$ epidepride and ${ }^{[123 I]} \beta$-CIT. Mov Disord 1998;13:319-323.

14. Preibisch C, Berg D, Hofmann E, et al: Cerebral activation patterns in patients with writer's cramp: a functional magnetic resonance imaging study. J Neurol 2001;248:10-17.

15. Lenz FA, Byl NN: Reorganization in the cutaneous core of the human thalamic principal somatic sensory nucleus (Ventral caudal) in patients with dystonia. J Neurophysiol 1999;82:3204-3212.

16. Hua SE, Garonzik IM, Lee JI, et al: Microelectrode studies of normal organization and plasticity of human somatosensory thalamus. J Clin Neurophysiol 2000; 17:559-574.

17. Elbert T, Candia V, Altenmüller E, et al: Alteration of digital representations in somatosensory cortex in focal hand dystonia. Neuroreport 1998;9:3571-3575

18. Bara-Jimenez W, Catalan MJ, Hallett M, et al: Abnormal somatosensory homunculus in dystonia of the hand. Ann Neurol 1998;44: 828-831.

19. Byl NN, McKenzie A, Nagarajan SS: Differences in somatosensory hand organization in a healthy flutist and a flutist with focal hand dystonia: a case report. J Hand Ther 2000;13:302-309.

20. Deuschl G, Toro C, Matsumoto J, et al: Movement-related cortical potentials in writer's cramp. Ann Neurol 1995;38:862-868.

21. Ceballos-Baumann AO, Sheean G, Passingham RE, et al: Botulinum toxin does not reverse the cortical dysfunction associated with writer's cramp: A PET study. Brain 1997;120:571-582.

22. Pujol J, Roset-Llobet J, Rosines-Cubells D, et al: Brain cortical activation during guitar-induced hand dystonia studied by functional MRI. Neuroimage 2000;12:257-267.

23. Tempel LW, Perlmutter JS: Abnormal vibration-induced cerebral blood flow responses in idiopathic dystonia. Brain 1990;113:691-707.

24. Rosenkranz K, Altenmüller E, Siggelkow S, et al: Alteration of sensorimotor integration in musician's cramp: impaired focusing of proprioception. Clin Neurophysiol 2000;111:2040-2045.

25. Frommer J: Idiopathic writer's cramp as a psychosomatic disorder. Zsch Psychosom Med 1992;38:49-62.

26. Schulze A, Jacob HW, Guckler A: Psychosomatic determinants of writer's cramp. Psychother Psychosom Med Psychol 1992;42:201-205

27. Windgassen K, Ludolph A: Psychiatric aspects of writer's cramp. Eur Arch Psychiatry Clin Neurosci 1991;241:170-176

28. Schmidt S, Wisser R, Heitmann R: Psychosomatic aspects of focal dystonia: two case reports. Psychother Psychosom Med Psychol 1994; $44: 247-250$.

29. Scheidt CE, Schuller B, Rayki O, et al: Relative absence of psychopathology in benign essential blepharospasm and hemifacial spasm. Neurology 1996;47:43-45.

30. Harrington RC, Wieck A, Marks IM, et al: Writer's cramp: not associated with anxiety. Mov Disord 1988;3:195-200.

31. Pai MN: The nature and treatment of writer's cramp. J Ment Sci 1947; 93:68-81.

32. Gibson HB: Writer's cramp: a behavioural approach. Behav Res Ther 1972;10:371-380

33. Cottraux JA, Juenet C, Collet L: The treatment of writer's cramp with multimodal behaviour therapy and biofeedback: a study of 15 cases. $\mathrm{Br}$ J Psychiatry 1983;142:180-183.

34. Zacher A: Writer's cramp-focal dystonia or psychogenic movement disorder? a critical literature study. Fortschr Neurol Psychat 1989;57: $328-336$
35. Ludolph AC, Windgassen K: Writer's cramp: a study of 30 cases. Nervenarzt 1992;63:462-466.

36. Gündel H, Wolf A, Xidara V, et al: Social phobia in spasmodic torticollis. J Neurol Neurosurg Psychiatry 2001;71:499-504.

37. Jabusch HC, Müller SV, Altenmüller E: Anxiety in musicians with focal dystonia and those with chronic pain. Mov Disord 2004. DOI: $10.1002 / \mathrm{mds} .20110$.

38. McGaugh JL: Memory-a century of consolidation. Science 2000;287: 248-251.

39. Ferry B, McGaugh JL: Role of amygdala norepinephrine in mediating stress hormone regulation of memory storage.Acta Pharmacol Sin 2000;21:481-493.

40. Packard MG, Cahill L, McGaugh JL: Amygdala modulation of hippocampal-dependent and caudate nucleus-dependent memory processes. Proc Natl Acad Sci U S A 1994;91:8477-8481.

41. Karni A, Meyer G, Rey-Hipolito C, et al: The acquisition of skilled motor performance: Fast and slow experience-driven changes in primary motor cortex (M1). Proc Natl Acad Sci U S A 1998;95:861-868.

42. Sripanidkulchai K, Sripanidkulchai B, Wyss JM: The cortical projection of the basolateral amygdaloid nucleus in the rat: A retrograde fluorescent dye study. J Comp Neurol 1984;229:419-431.

43. Craig KD: Emotional aspects of pain. In Wall PD, Melzack R (eds): Textbook of Pain. Edinburgh, Churchill Livingstone, 1984, pp. $153-161$.

44. Linton SJ: A review of psychological risk factors in back and neck pain. Spine 2000;25:1148-1156.

45. Monsen K, Havik OE: Psychological functioning and bodily conditions in patients with pain disorder associated with psychological factors. Br J Med Psychol 2001;74:183-195.

46. Asmundson GJ, Norton GR, Jacobson SJ: Social, blood/injury, and agoraphobic fears in patients with physically unexplained chronic pain: are they clinically significant? Anxiety 1996;2:28-33.

47. Haerkaepaeae K: Psychosocial factors as predictors for early retirement in patients with chronic low back pain. J Psychosom Res 1992;36: 553-559.

48. Charness ME: Unique upper extremity disorders of musicians. In Millender LH, Louis DS, Simmons BP (eds): Occupational Disorders of the Upper Extremity. New York, Churchill Livingstone, 1992, pp. 227-252.

49. Newmark J, Hochberg FH: Isolated painless manual incoordination in 57 musicians. J Neurol Neurosurg Psychiatry 1987;50:291-295.

50. Smith BH, Elliott AM, Chambers WA, et al: The impact of chronic pain in the community. Fam Pract 2001;18:292-299.

51. Fishbein M, Middlestadt E, Ottati V, et al: Medical problems among ICSOM musicians: overview of a national survey. Med Probl Perform Art 1988;3:1-8

52. Clayton EC, Williams CL: Adrenergic activation of the nucleus tractus solitarius potentiates amygdala norepinephrine release and enhances retention performance in emotionally arousing and spatial memory tasks. Behav Brain Res 2000;112:151-158.

53. Williams CL, Men D, Clayton EC, et al: Norepinephrine release in the amygdala after systemic injection of epinephrine or escapable footshock: contribution of the nucleus of the solitary tract. Behav Neurosci 1998;112:1414-1422.

54. Quirarte GL, Roozendaal B, McGaugh JL: Glucocorticoid enhancement of memory storage involves noradrenergic activation in the basolateral amygdala. Proc Natl Acad Sci U S A 1997;94:14048-14053. 


\section{APPENDIX}

\section{Questionnaire}

Please answer the following questions by checking the appropriate box. If you answer yes to any of the questions, please try to specify since when you have experienced the respective fears or anxieties by using the following terms:

- always

- long before the onset of the movement disorder*

- after the onset of the movement disorder*

- not any more

\begin{tabular}{|c|c|c|c|}
\hline & No & Yes & $\begin{array}{l}\text { Since } \\
\text { When? }\end{array}$ \\
\hline \multicolumn{4}{|l|}{ Are you suffering from acute (considerable) stage fright? } \\
\hline \multicolumn{4}{|l|}{$\begin{array}{l}\text { Have you ever have experienced anxiety attacks (i.e., were you suddenly and } \\
\text { unexpectedly overcome by strong fear or apprehension in a situation normally } \\
\text { considered nonthreatening)? }\end{array}$} \\
\hline \multicolumn{4}{|l|}{$\begin{array}{l}\text { Have you ever felt anxious, tense, or worried for a prolonged period ( } \geq 6 \text { months)? } \\
\text { Did or do you often worry about events that are unlikely to occur? }\end{array}$} \\
\hline \multicolumn{4}{|l|}{$\begin{array}{l}\text { Some people are afraid of going out alone; encountering crowds of people; or traveling } \\
\text { by car, bus, or train. Have you ever experienced such a fear? }\end{array}$} \\
\hline \multicolumn{4}{|l|}{$\begin{array}{l}\text { Some people are afraid to be, speak, or work in the presence of others, so they avoid } \\
\text { those situations or endure them only with great discomfort. Have you ever had anxious } \\
\text { feelings of that kind? }\end{array}$} \\
\hline $\begin{array}{l}\text { In certain situations, some people experience intense anxiety (e.g., fear of heights, } \\
\text { fear of flying, fear of enclosed spaces), so they try to avoid those circumstances. } \\
\text { Have you ever had anxious feelings of that kind? }\end{array}$ & & & \\
\hline
\end{tabular}

*In the questionnaires for patients with chronic pain syndromes, movement disorder was replaced by pain.

This is an English translation of the questionnaire that was designed to assess anxiety disorders. The original questions were written in German. 